\title{
Thermally regulated valve for minute flows
}

\author{
Hugo Nguyen, Johan Bejhed, Johan Köhler, and Greger Thornell \\ The Ångström Space Technology Centre, Department of Engineering Sciences, Uppsala \\ University, Sweden
}

\begin{abstract}
Investigated here is a gas valve using a microstructured, ridge-equipped silicon valve lid and a stainless steel valve seat clamped together in an aluminium cylinder. The difference in coefficient of thermal expansion of these components makes the valve open on increasing the temperature as treated theoretically in a straightforward approach. The elastic deformation of the system acts to shift the opening temperature, whereas other properties affect the sensitivity (i.e. the flow rate vs. temperature) of the valve. By means of a helium leak detector, a typical flow rate increase from $1 \times 10^{-8}$ to $1 \times 10^{-4} \mathrm{scc} / \mathrm{s}$ was observed, after a single breaking-in, by increasing the temperature from $12^{\circ} \mathrm{C}$ to around $97^{\circ} \mathrm{C}$. Microscopy confirmed a tolerance for particles of up to a few micrometer in diameter, but also revealed larger particles to be a possibly failure mode. White light interferometry shows that the valve seat is plastically deformed to a depth of $0.25-1.2 \mu \mathrm{m}$ by the ridge being $2.6 \mu \mathrm{m}$ high - with the rest being attributed to elastic deformation. Equations on the exponential form are well fitted to the flow rate vs. temperature graphs.
\end{abstract}

Keywords: valve, interface, silicon, stainless steel, ridge, thermal, thermally regulated/regulation, particle

\section{Introduction}

Applied microfluidics is a vast and important field since the advent of microsystems, and has been the topic of several reviews, focusing on different aspects. Van de Pol and Branebjerg [1] present a compilation of published micropumps, ink-jet heads, microvalves, micro flowsensors, and micro liquid-handling systems. The seminal review by Gravesen et al. [2] adds relevant fluid mechanics to the picture, and points to the increasing use of numerical modelling, and also conventional assumptions' frequent breakdown in microscale. It also includes an insightful treatise on microfluidic systems. Shoji and Esashi [3] discuss microvalves, micropumps, and microflow sensors in terms of actuation principles, and points out the possibility to enhance precision by the combination of pertinent devices into systems. Stemme [4] starts from processes and principles, and limits his review to liquid-handling devices. Zengerlee and Sandmaier [5] update the then recent advances in microfluidics devices for fluid regulation and control. Specifically, the authors identify a growing potential for higher performance microvalves, in terms of temperature range, lower power consumption, smaller size and mass, and feasible sensor integration. Henning [6] focuses his work on thermopneumatic valves and systems, together with comprehensive analysis of expected performances, and with comparisons to other techniques. Henning also addresses the low-leakage challenge, and presents a successful shut-off valve. Mueller [7] clearly states limits for leakage in micropropulsion valves, and presents a successful example with Yang et al. [8]. Other recent advanced microvalves include work from several groups, e.g. [9-16]. Also, a systematic approach to mictrofluidic interfacing, including microvalves, is presented by Han and Frazier [17].

Inspired by the above works and previous work [18] on a connector interfacing a silicon microstructure with a stainless steel macropart for fluidic applications, the authors of this 
work set out to further investigate a similar structure's thermal characteristics with the objective to use it as a thermally activated valve for precise control of extremely small gas flows from high-pressure sources. Here, the realisation and performance of such a valve are presented. Specifically, the observed temperature limitations of the previous passive connector have been turned into an active advantage - providing the actuation of a thermally regulated microvalve. Here, the relative thermal expansions of the stiff silicon part and the softer stainless steel counterpart work to relieve the initially clamped condition, eventually allowing the gas to flow through the device on a slight temperature increase. This microvalve concept has been characterised with respect to mounting conditions, size of interface and applied pressure, in order to evaluate its performance.

\section{Concept}

In essence, the device consists of a hard and relatively thin part (typically a silicon microsystem) and a longer and softer part (typically a macroscopic steel nipple) making up the valve lid and the valve seat, respectively. These parts are aligned to each other and clamped firmly together so that the micropart blocks the flow channel - an axial hole - of the nipple. On controlled heating above the assembling temperature, the clamping stress is gradually relieved because of the difference in thermal expansion coefficient between the clamp and the combined valve seat and valve lid, and gas is let through.

The principle of operation is schematically shown in Fig. 1, where a stainless steel supporting insert and stop screw have been added, and the clamping structure has been assumed to be an aluminium cylinder, as in the experiments conducted in this study. (In the following, the steel parts could be treated as a single unit, however.)

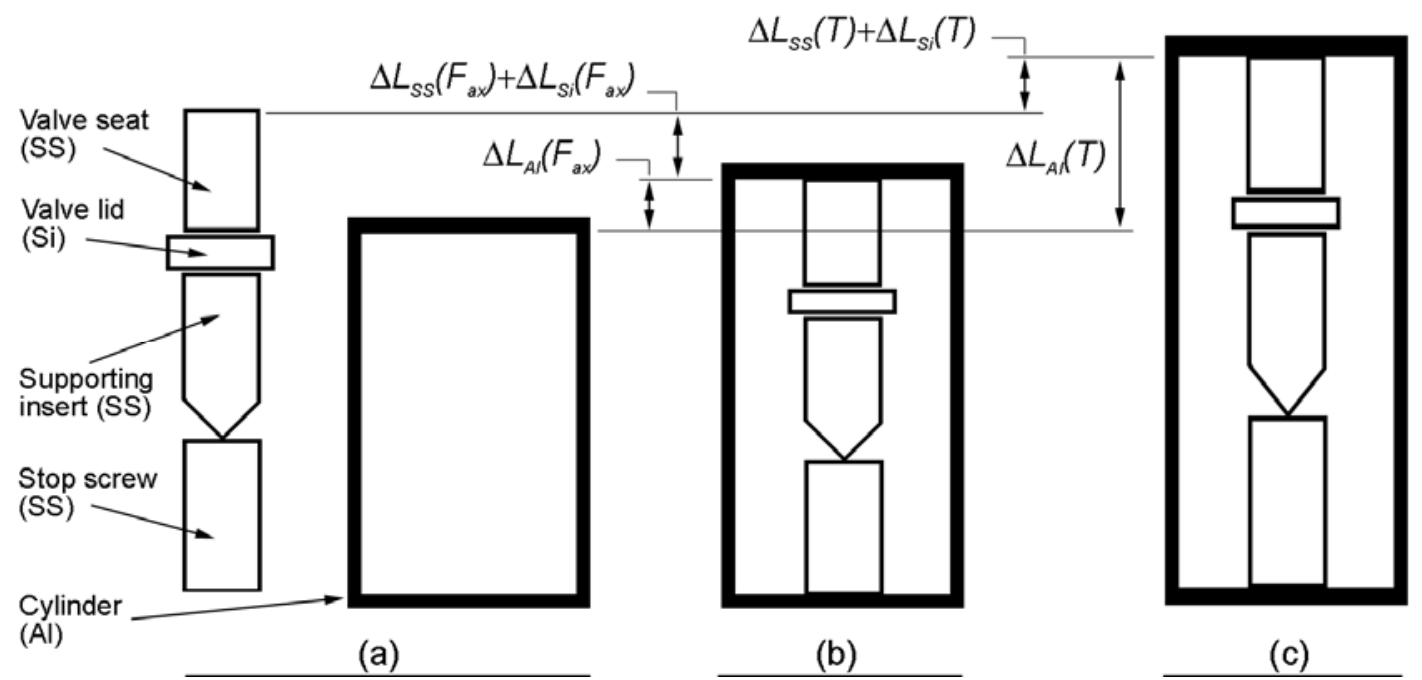

Figure 1. The unassembled and unstressed valve lid, valve seat and supporting parts, and the clamping cylinder, (a), being assembled and clamped leading to an elongation of the cylinder and a compression of the other parts, (b), and this assembly being heated to the point where the faster expanding cylinder has relieved the parts from elastic deformation, and, in addition, compensated for the thermal expansion obtained therewith, and so decreased the valve's contact pressure to zero, (c). (SS, Si and Al, stand for stainless steel, silicon and aluminium, respectively. $\Delta \mathrm{L}$ with its dependence on axial mounting force, $F_{\mathrm{ax}}$, and temperature, $T$, denotes changes in length.)

To clamp the system and cause the necessary deformation - initially treated as purely elastic $-\mathrm{a}$ torque is applied to the stop screw (see Fig. 1). Taking into account the thread friction, as 
described by the friction coefficient, $\mu$, the relationship between this torque, $\tau$, and the resulting axial force, $F_{a x}$, obeys

$$
\tau=F_{a x} \cdot \frac{d_{p}}{2} \cdot \frac{\cos \theta_{n} \tan \alpha+\mu}{\cos \theta_{n}-\mu \tan \alpha}
$$

where $d_{p}$ is the pitch diameter, and $\theta_{n}$ and $\alpha$ the angles of the stop screw's thread profile [19].

Now, assuming that the gas will start to flow through the valve when the stress is completely relieved, this initial deformation will act as a bias delaying the activation and opening of the valve to a higher temperature - henceforth referred to as the activation temperature. A rough estimation of this delay could be based on the calculation of the elastic deformation at the assembling temperature, and then looking for the temperature where the faster expanding cylinder has compensated both for this deformation and the additional thermal elongation of the inner parts at this point, Fig. 1. The initial deformation is a function of the applied force, i.e. $\mathrm{F}_{\mathrm{ax}}$, and the Young's modulus, $\mathrm{E}$, length, $\mathrm{L}$, and cross-sectional area, A, of the components, whereas the thermal expansion is a function of the difference in temperature to the assembly temperature, $\Delta \mathrm{T}$, and the length and coefficient of thermal expansion, $\alpha$, of the components. Treating the three steel parts as a single piece, this gives

$$
\begin{aligned}
& L_{A l} \alpha_{A l} \Delta T=\Delta L_{A l}\left(F_{a x}\right)+\Delta L_{S S}\left(F_{a x}\right)+\Delta L_{S i}\left(F_{a x}\right)+\Delta L_{S S}(T)+\Delta L_{S i}(T) \\
& =L_{A l} \frac{F_{a x}}{E_{A l} A_{A l}}+L_{S S} \frac{F_{a x}}{E_{S S} A_{S S}}+L_{S i} \frac{F_{a x}}{E_{S i} A_{S i}}+L_{S S} \alpha_{S S} \Delta T+L_{S i} \alpha_{S i} \Delta T,
\end{aligned}
$$

which is readily solved for $\Delta \mathrm{T}$ in

$$
\Delta T=F_{a x} \frac{\frac{L_{A l}}{E_{A l} A_{A l}}+\frac{L_{S S}}{E_{S S} A_{S S}}+\frac{L_{S i}}{E_{S i} A_{S i}}}{L_{A l} \alpha_{A l}-L_{S S} \alpha_{S S}-L_{S i} \alpha_{S i}} .
$$

After further heating after this activation, the valve seat and valve lid will separate according to

$$
\Delta L_{S t r}=\Delta L_{A l}-\left(\Delta L_{S S}+\Delta L_{S i}\right)=\left(L_{A l} \alpha_{A l}-\left(L_{S S} \alpha_{S S}+L_{S i} \alpha_{S i}\right)\right) \Delta T_{S t r},
$$

where the subscript Str denotes stroke. (This expression was also used in [18], in order to determine the temperature range limits for sealing.)

\section{Materials and methods}

\section{Device fabrication}

The two parts that constitute the interface of the valve are the valve lid and valve seat. The former, Fig. 2, was micromachined from a $1 \mathrm{~mm}$ thick 4-inch silicon wafer by means of deep reactive ion etching, DRIE, with two mask steps from each side including ID labelling on the backside. The ridge on the side mating the valve seat was designed to have a height and width of 3 and $40 \mu \mathrm{m}$, respectively, whereas both 2.0 and $3.0 \mathrm{~mm}$ were used for (inner) ridge diameter, valve lid A and B, respectively. With an exception for sacrificial suspensions, the 8 mm diameter valve lid chips were contoured by etching, and subsequently diced out. 


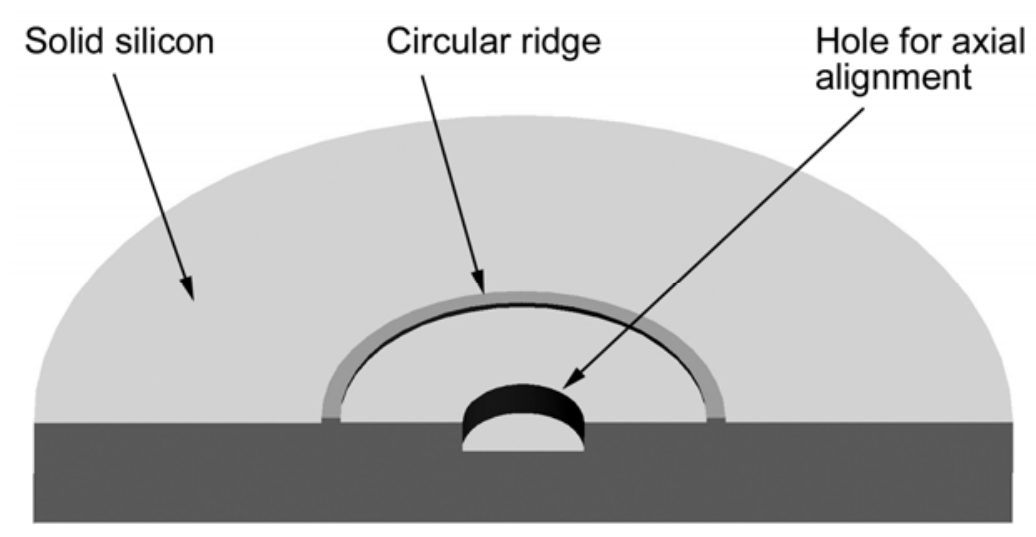

Figure 2. Design of silicon valve lid in cross-section.

The valve seat was made of stainless steel ASTM316 (European: EN1.4436) in form of an 8 $\mathrm{mm}$ diameter nipple with a centre channel with a diameter of $1 \mathrm{~mm}$. An automated grinding machine (Phoenix 4000/4000V, Wirtz-Buehler GmbH, Germany) was used to obtain a flat and smooth surface perpendicular to the nipple axis. The second last grinding step was made with a 1200 mesh grinding paper, and the last step with grinding paper with a 4000 mesh paper with an applied force decreasing to zero, and held there for $3 \mathrm{~min}$ at $250 \mathrm{rpm}$. A set of four valve seats were grinded and polished per batch. Only the specified steps were needed for reconditioning of used seats.

\section{Test equipment and assembly}

After machining, the parts were carefully cleaned in acetone followed by isopropanol, and blown dry with nitrogen. Before assembling into the test jig, Fig. 3 [18], Nitto tape (SWT10 or SWT20) was used to remove particles from the critical surfaces. A centring pin with a diameter of $1 \mathrm{~mm}$ was inserted into the valve seat channel and left to protrude about $0.3 \mathrm{~mm}$ above the surface of the valve seat. Subsequently, the aluminium cylinder was screwed onto the nipple, and nitrogen flushed through it to blow away any particles that might have been generated on the insertion. The valve lid was then dropped into the cylinder and the valve seat part gently tapped, until the lid was observed rotating on the centring pin indicating it had been aligned to the channel. Following on this, the supporting insert was carefully lowered into the cylinder using tweezers. A pair of custom-made tongs, and guide trenches on the supporting insert, prevented the insert from turning but allowed for axial movement, Fig. 3(a). On having secured the assembly with the stop screw, tightened with a torque wrench, the centring pin was withdrawn.

The full testing assembly, Fig. 3(b), is basically that of [18] with minor adjustments made to the supporting insert to make the alignment easier and with an exception for the o-ring which here was made of Viton. The assembly consists of a high-pressure part (the valve seat side) connected to a helium tube via a standard pressure regulator and a pressure sensor, and a vacuum part (valve lid side) connected to a helium-triggered leak detector (HLT100, Baltzers) served by a turbo pump. Covering the location of the valve fairly well, a heater is wound on the outside of the high-pressure part. A thermocouple was placed in a hole ending a couple of centimetres from the valve interface. 
(a)

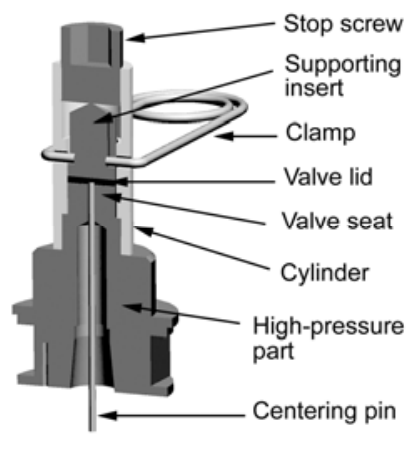

(b)

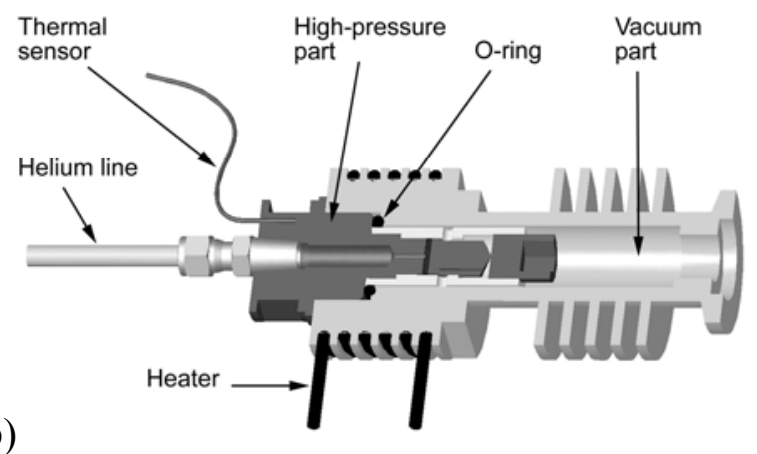

Figure 3. Cross section showing assembling of valve parts, (a). and cross-section showing the full testing assembly including gas connections, temperature sensor and heater, (b).

The power to the heater, and data sampling from the temperature sensor and pressure sensor, as well as the leak detector, were computer-controlled in the Labview environment (version 7.0, National Instruments) and by means of a PCI card (PCI-1711S, Advantech).

\section{Evaluation}

To obtain reproducible starting conditions, each assembly was cooled down to $9-10^{\circ} \mathrm{C}$ by ice water, subjected to a first leak test and allowed to passively reach $12^{\circ} \mathrm{C}$ in a roomtemperature ambient. After this, and on confirmation of a stable and negligible leak rate base level, heating (at approximately $32 \mathrm{~W}$ ) with simultaneous leak and temperature logging were commenced. The pressure and maximum test temperature were varied according to Table 1 . To investigate the breaking in of the valves, and examine reproducibility, all samples were tested repeatedly according to Table 1 without intermediate disassembly. Sample A was mounted with a torque of $4.0 \mathrm{Ncm}$, sample B with $4.5 \mathrm{Ncm}$.

Table1. Experimental conditions and number of tests.

\begin{tabular}{crcc}
\hline valve lid & $\begin{array}{c}\text { pressure } \\
\text { (bars) }\end{array}$ & $\begin{array}{c}\text { number } \\
\text { of tests }\end{array}$ & $\begin{array}{c}\text { approx. maximum test } \\
\text { temperature }\left({ }^{\circ} \mathrm{C}\right)\end{array}$ \\
\hline \hline A & 2 & 6 & 88 \\
A & 8 & 5 & 86 \\
A & 10 & 4 & 81 \\
\hline B & 2 & 4 & 98 \\
B & 5 & 3 & 92 \\
B & 8 & 4 & 90 \\
B & 10 & 3 & 89 \\
\hline
\end{tabular}

After testing, the valve seat and valve lid were investigated by optical microscopy, as well as scanning electron microscopy, SEM (Zeiss, DSM 960A), and white light interferometry, WLI (WYKO NT2000, model PZ-06-CS-SF, Mikro Precision Instruments, USA).

\section{Results}

Valve lid A with a $2 \mathrm{~mm}$ diameter ridge of $2.6 \mu \mathrm{m}$ height (as opposed to the design height of $3 \mu \mathrm{m})$ and its corresponding valve seat imprint is shown in Fig. 4 and Fig. 5, respectively. The depth of the plastic deformation as quantified in Fig. 5(b), varied according to Table 2, but was less than half the height of the ridge. With all assemblies, embankments, Fig. 5, occurred to various extent. Notable in this figure are both the faceting of these embankments, and the shallow scratches from polishing. 


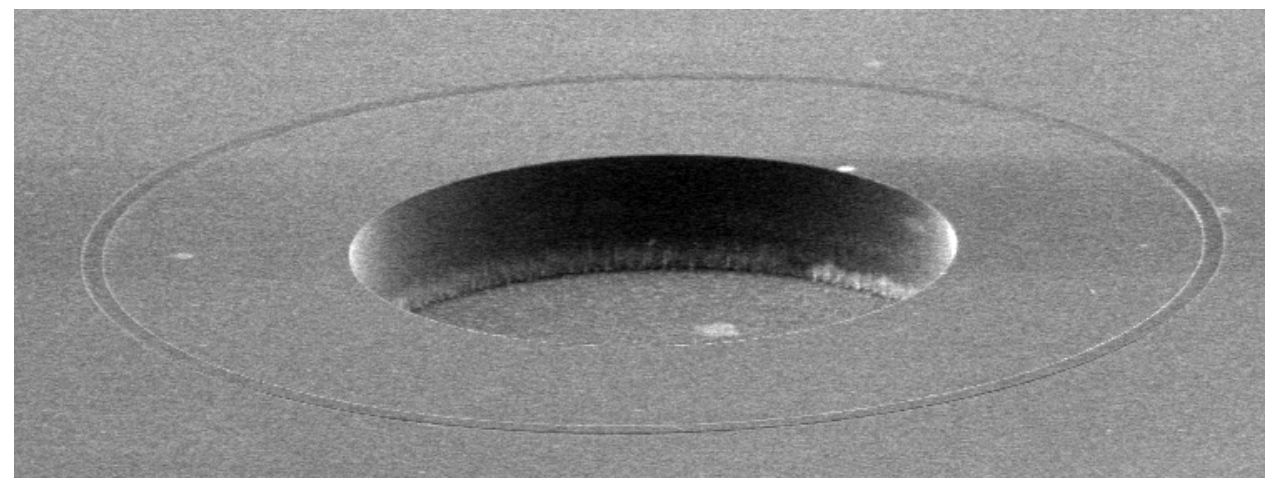

Figure 4. SEM picture of valve lid A with a $2 \mathrm{~mm}$ diameter ridge.

(a)
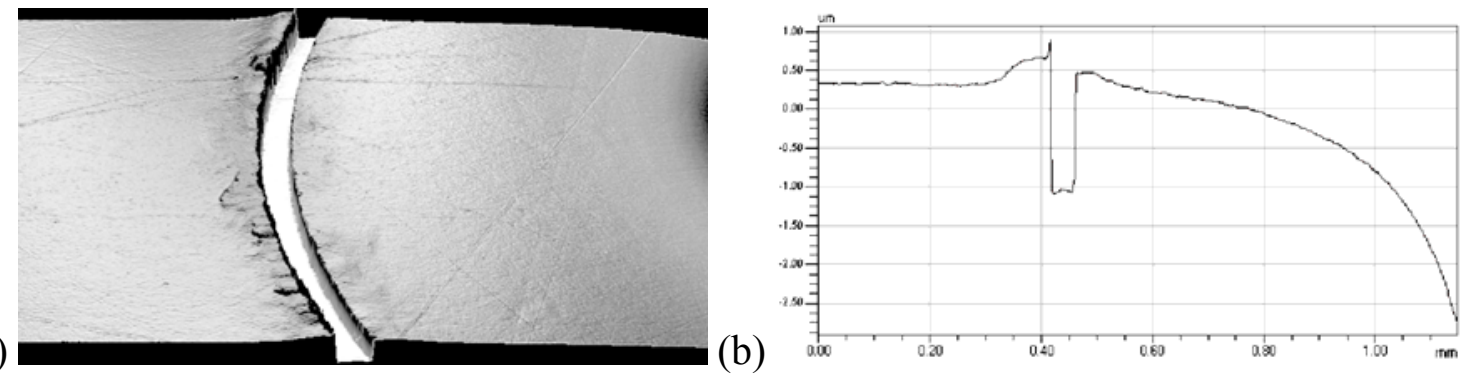

Figure 5. White light interferometer picture of valve seat imprint, (a), and a surface profile (also WLI) across the centre of this field of view.

Table 2. Depth of imprint, theoretical activation temperature, observed regulation range for last run, and coefficients of the fitted equation $q=m \cdot e^{n T}$ and its $R^{2}$ value for a selection of tests.

\begin{tabular}{cccccccc}
\hline $\begin{array}{c}\text { Valve } \\
\text { lid }\end{array}$ & $\begin{array}{c}\text { Pressure } \\
(\text { bar })\end{array}$ & $\begin{array}{c}\text { Depth of } \\
\text { imprint } \\
(\mu \mathrm{m})\end{array}$ & $\begin{array}{c}\text { Theoretical } \\
\text { activation } \\
\text { temperature } \\
\left({ }^{\circ} \mathrm{C}\right)\end{array}$ & $\begin{array}{c}\text { Observed } \\
\text { regulation } \\
\text { range }\left({ }^{\circ} \mathrm{C}\right)\end{array}$ & $\mathrm{m}$ & $\mathrm{n}$ & $\mathrm{R}^{2}$ \\
\hline $\mathrm{A}$ & 2 & $0.30-1.2$ & 42 & 15.4 & $2 \times 10^{-9}$ & 0.12 & 0.97 \\
$\mathrm{~A}$ & 10 & $0.30-1.2$ & 42 & 10.1 & $8 \times 10^{-12}$ & 0.21 & 0.99 \\
$\mathrm{~B}$ & 2 & $0.25-1.1$ & 46 & 7.9 & $4 \times 10^{-15}$ & 0.25 & 1.00 \\
$\mathrm{~B}$ & 10 & $0.25-1.1$ & 46 & 7.1 & $8 \times 10^{-19}$ & 0.36 & 1.00 \\
\hline
\end{tabular}

Figure 6 shows a typical (valve lid B) stabilized valve characteristic, i.e. the flow rate of the helium through the valve as a function of temperature after a running-in test. With the peaks stemming from change of measurement range of the leak detector removed, curves on the form $\mathrm{q}=\mathrm{m} \cdot \mathrm{e}^{\mathrm{nT}}$, where $\mathrm{q}$ is the flow rate and $\mathrm{T}$ the temperature, were fitted to the segment ranging from $1 \times 10^{-5}$ to $10 \times 10^{-5} \mathrm{scc} / \mathrm{s}$ GHe considered to be the effective regulation range. The coefficients $\mathrm{m}$ and $\mathrm{n}$ of the fitted curves, and the fitting errors in terms of $\mathrm{R}^{2}$ are presented in Table 2. This table also contains the theoretically estimated activation temperature (from Eq. 3), and the observed regulation ranges for a selection of tests. 


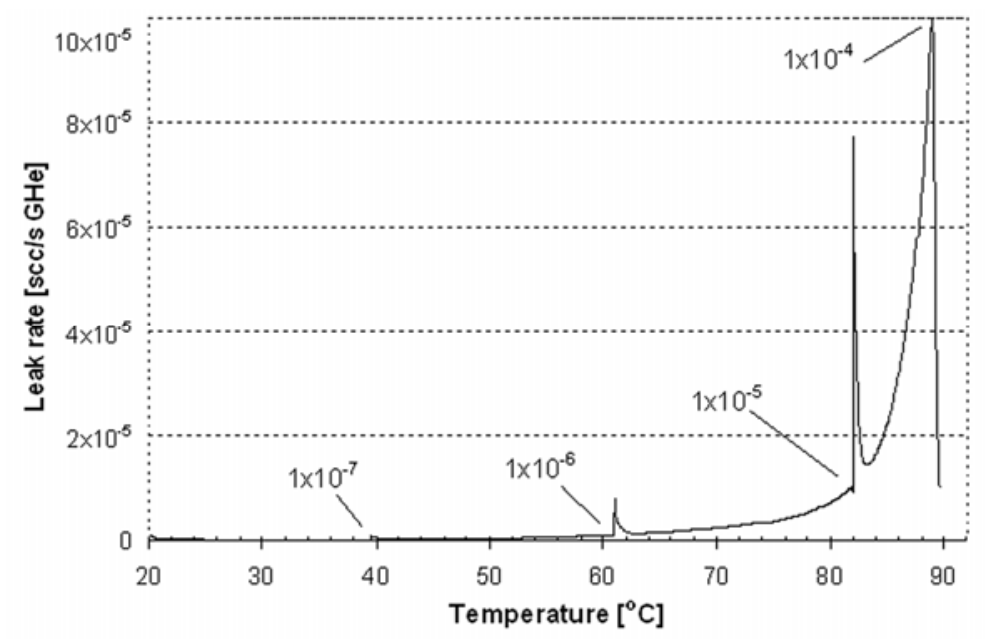

Figure 6. Typical helium leakage versus actuating temperature for assembly with valve lid B subjected to a pressure of 10 bar. (Vertical peaks arise because of switching of measurement range and are pure apparatus artefacts.)

The first test run - virgin run - of each assembly always resulted in an offset of several degrees towards higher temperature in comparison with subsequent curves, whereas brokenin valves showed characteristics reproducible within $\pm 0.8^{\circ} \mathrm{C}$.

As for the pressure dependence, the temperature corresponding to a leak rate of $1 \times 10^{-4} \mathrm{scc} / \mathrm{s}$ GHe was chosen as a point of reference. This is plotted versus pressure and ridge radius in Figure 7.

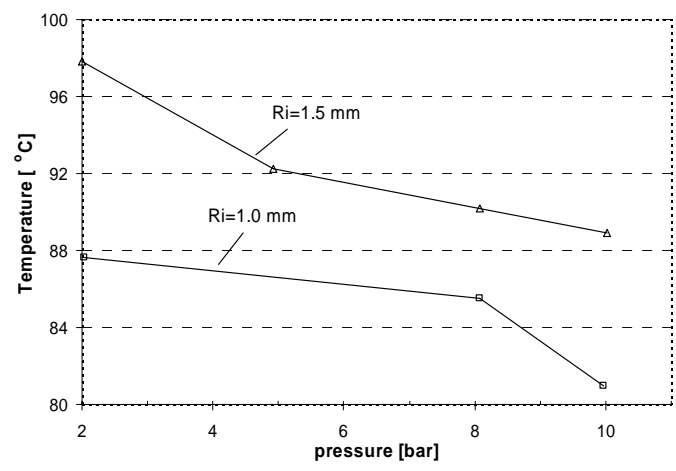

Figure 7. Dependence of the temperature corresponding to a flow rate of $1 \times 10^{-4} \mathrm{scc} / \mathrm{s}$ GHe on pressure for the inner ridge radius, $\mathbf{R}_{\mathrm{i}}$.

On the investigation of a preliminary assembly with a valve lid of type $\mathrm{B}$, a scatter of silicon fragments across the valve lid was observed. These apparently originated from incomplete etching of the centre hole resulting in silicon micrograss relased during assembling. A few of the fragments were located in the contact at the interface between the ridge and nipple. A particularly large, rod-shaped fragment extending across the ridge imprint is shown in Fig. 8. This caused an initial leak rate of $5 \times 10^{-5} \mathrm{scc} / \mathrm{s}$ GHe under a pressure of 10 bar, wherefore further testing of the assembly was not made. A corresponding chipping damage of a few micrometers in size was confirmed at the ridge. However, the valve lid was in good condition and could be successfully reused. 


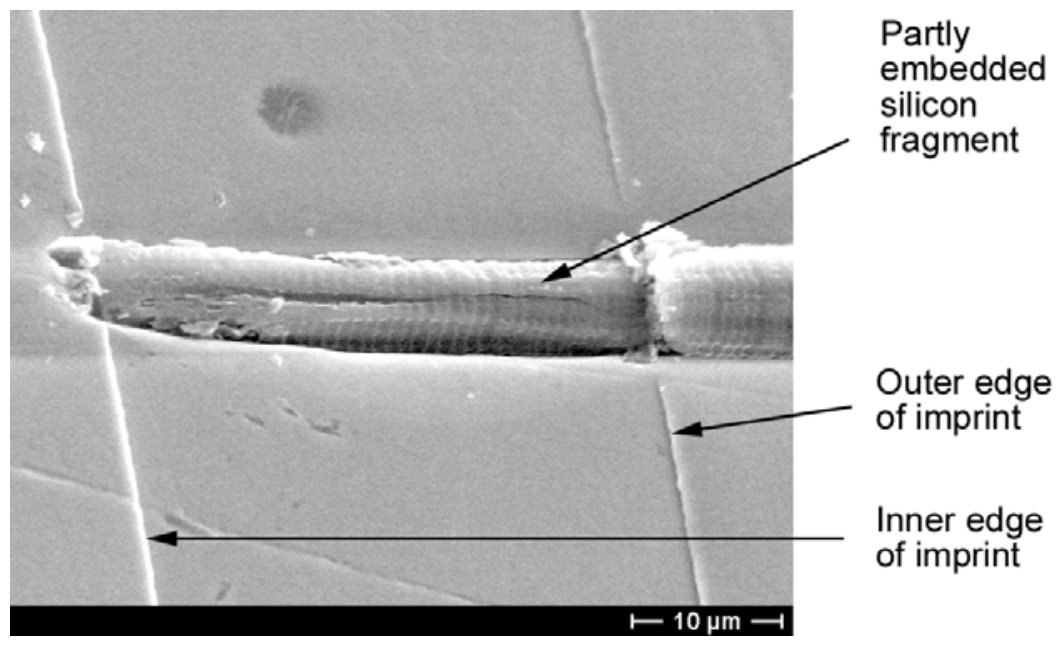

Figure 8. A rod-shaped silicon fragment pressed into the stainless steel valve seat by the ridge of a silicon valve lid of type $B$.

In general the valve lids were completely unharmed after engagement with the valve seats. In an $a d-h o c$ series of experiments, a valve lid was reused three times with three fresh seats creating imprints in them, but without any visible damage of the lid itself.

\section{Discussion}

Obviously the complete valve system offers several ways to alter the activation temperature by proper design considerations. Even without thoroughly comparing these with each other, one can easily understand that the activation temperature for a given assembly can be somewhat adjusted by changing the lengths of the components or by applying another torque, or perhaps to a larger extent by changing the material of the components.

Using Eq. 3 and typical material parameters for the assembly used here, it might come as a surprise that the theoretical activation temperature is not very sensitive to changes in the length of the assembly, exhibiting a shift of just a few degrees Celsius on an extension by nearly a factor of ten of all parts but the valve lid. In general, a decrease in length of the assembly studied here will raise the activation temperature and compress the effective regulation range, i.e. the right part of the flow rate vs. temperature graph, whereas a length increase will lower the activation temperature and expand the effective regulation range.

To see what could happen on altering the material properties, one could imagine replacing stainless steel with aluminium and vice versa, as a result of which the activation would occur on cooling, instead of heating, from the temperature of assembling. Equation 3, as it reads, or after eliminating a few less important terms (as the silicon contributions in this case), provides a means of studying a manifold of variable combinations. Such a sensitivity or optimization analysis is not within the scope of this work, however. It should be stressed that the above reasoning is valid only for elastic deformation. In the case of plastic deformation, all the original lengths in equations 3 and 4 should be decreased with their respective plastic strain, theoretically. In practice, however, a change of a few micrometers of an original length of several millimetres would not result in other than a negligible change in activation temperature.

For the parts here involved, the stroke change per degree Celsius, as obtained from eq. 4, is $0.20 \mu \mathrm{m} /{ }^{\circ} \mathrm{C}$. Since the ridges had a height of $2.6 \mu \mathrm{m}$, the theoretical temperature increase of $13^{\circ} \mathrm{C}$ is needed to disengage the ridge from the bottom of its imprint in the valve seat. 
With the deepest imprint observed (valve seat A) being $1.2 \mu \mathrm{m}$ for a contact pressure being 6.3 times higher than the valve seat elasticity limit, $1.4 \mu \mathrm{m}$ of the $2.6 \mu \mathrm{m}$ high ridge is lost to elastic deformation. (Most of this is of course attributable to the valve seat, being much weaker than silicon). Also the other parts of the assembly, such as the aluminium cylinder, the rest of the valve seat, the supporting insert, and the stop screw undergo elastic and plastic deformation as well - at least locally. (Only the silicon part will suffer from pure elastic deformation.) From eq. 3, the temperature increase necessary to relieve the assembly from elastic strain in the above case can be calculated to $18^{\circ} \mathrm{C}$ implying an activation temperature of $42^{\circ} \mathrm{C}$ as the assembling was made at a room temperature of $24^{\circ} \mathrm{C}$. Nonetheless, a gradual increase in flow rate was observed prior to this in all tests. For valve lid A, for instance, although not visible in Fig. 6, the flow had increased by two orders of magnitude from its background level $\left(1 \times 10^{-8} \mathrm{scc} / \mathrm{s}\right)$ on reaching the predicted activation temperature. This does not necessarily indicate that the mechanical bias was relieved earlier or that the estimated stress doesn't have to be relieved in order for the valve to open in the ideal case. More likely, the torque translated to a non-uniform deformation. Hence, there could very well be a net positive pressure on the valve interface despite this flow increase. For this reason, the activation temperature of these valves should be verified through measurement.

For each assembly the activation temperature and the length of the regulation range could be reproduced. Even after a compensation for using different torques, different assemblies with equivalent parts often differed from each other in this respect, however. The virgin curves was observed with all assemblies, correlated vaguely with the succeeding ones, and only stress the importance of running-in the valve in an actual application.

The equations, Table 2, fitted to the regulation (right-hand) part of the flow vs. temperature graphs fail to be easily associated with analytically derived expressions, even if the ridge and imprint part of the interface is liberally approximated with a slot. Likely reasons for this include the non-parallelity of the valve lid and valve seat, the curvature of the latter, the roughness of the ridge's sidewalls, the embankments, and probably most important the pinching occurring between the ridge and its imprint because of the thermal mismatch. However, the equations describe well the behaviour of the valves, and could hence be used for prediction and for development of control algorithms.

As for the failure mode, Fig. 8, it is obvious that helium started to flow through the valve already when the valve lid was still pressing on its seat with maximum force. It is not clear if the rather extreme particle depicted is the reason for this. On valve seats closing perfectly well, particles up to a few micrometers in size were seen to be completely embedded in the imprint with no effect on the valve performance, suggesting that the valve is robust enough to handle unfiltered tube gas, as well as the assembling environment of an ordinary laboratory - at least given the stated assembling precautions. Normal scratches from polishing were not found to affect the valve performance - other than perhaps by contributing to the base level of the leak rate.

The attempt to find correlation between the flow rate of helium and its pressure and the ridge radius, Fig. 7, did not lead to data well-behaved enough to reveal any other correlation than an obvious one: that the higher the helium pressure, the earlier the flow rate reached the maximum level possible to measure with the equipment used. Interestingly the larger ridge, which intuitively should reach this point earlier than the smaller one for any given pressure, 
was higher in temperature. The reason for this is unclear, but a particle contamination cannot be ruled out.

\section{Conclusion}

A gas valve concept based on the use of different effective coefficients of thermal expansion for a valve seat and lid, and their clamping has been demonstrated and evaluated. Typically, flows in the range from $1 \times 10^{-8}$ to $1 \times 10^{-4} \mathrm{scc} / \mathrm{s}$ were reproducibly controlled, after a single breaking-in, by increasing the temperature from $12^{\circ} \mathrm{C}$ to $98^{\circ} \mathrm{C}$. Fitting of equations to these ranges, did not associate with analytically derived expressions describing fluidic flows through separated surfaces or surface features, but matched experimental data well (with $\mathrm{R}^{2}$ values from 0.97 to 1.00 ) and hence permit for development of control algorithms.

A straightforward analytical treatment shows that the material stiffnesses and, of more relevance, the coefficients of thermal expansion, provide good means to adjust the opening temperature and sensitivity (i.e. degree of flow rate increase with temperature), whereas a change of the length of the system is of less effect.

The valve proved to be robust in allowing for particles normally present in unfiltered tube gas and laboratory environment by embedding them in the softer part - here being the stainless steel valve seat.

\section{Acknowledgement}

The authors would like to express their gratitude to the European Space Agency, who is the sponsor of this project falling under the Micro/Nano Satellite Technologies project (ESA contract number 11041/04/NL/PM).

\section{References}

[1] van de Pol, F. C. M. And J. Branebjerg, Micro Fluid-Handling Systems - state of the art and opportunities, 5th Int. Conf. Advanced Robotics, 19-22 June, Pisa, Italy, pp 283$290,1991$.

[2] Gravesen, P., J. Branebjerg, and O Søndergård Jensen, Microfluidics - a review, Journal of Micromechanics and Microengineering, 3, pp 168-182, 1993.

[3] Shoji, S. and M. Esashi, Microflow devices and systems, Journal of Micromechanics and Microengineering, 4, pp157-171, 1994.

[4] Stemme, G. Micro Fluid Sensors and Actuators, $6^{\text {th }}$ Int. Symp. Micro Machine and Human Science, 4-6 Oct, Nagoya, Japan, pp 45-52, 1995.

[5] Zengerle, R. and H. Sandmaier, Microfluidics, $7^{\text {th }}$ Int. Symp. Micro Machine and Human Science, 2-4 Oct, Nagoya, Japan, pp 13-20, 1996.

[6] Henning, A. K., Microfluidic MEMS, Proc. IEEE Aerospace Conf. 1998, 21-28 Mar, Snowmass at Aspen, Colorado, 1, pp 471-486, 1998.

[7] Mueller, J., Review and applicability assessment of MEMS-based microvalve technology for microspacecraft propulsion, in Micropropulsion for small spacecraft, eds. M. M. Micci and A. D. Ketzdever, AIAA Progress in Astronautics and Aeronautics, 187, pp 449-476, 2000. 
[8] Yang, E-H., C. Lee, J. Mueller, and T. George, Leak-tight Piezoelectric Microvalve for High-Pressure gas Micropropulsion, Journal of Microelectromechanical systems, 13 (5), pp 799-807, 2004.

[9] Rich, C. A. and K. D. Wise, A High-Flow Thermopneumatic Microvalve with Improved Efficiency and Integrated State Sensing, Journal of Microelectromechanical Systems, 12 (2), pp 201-208, 2003.

[10] Braun, S., S. Haasl, S. Sadoon, A. S. Ridgeway, W. Van der Wijngart, and G. Stemme, Small footprintknife gate microvalves for large flow control, 13th Int. Conf. Solid State Sensors, Actuators and Microsystems, Seoul, Korea, June 5-9, pp. 329-332, 2005.

[11] Zhao, H., K. Stanley, Q. M. Jonathan Wu, E. Czyzewska, Structure and characterization of a planar normally closed bulk-micromachined piezoelectric valve for fuel cell applications, Sensors and Actuators A, 120, pp 134-141, 2005.

[12] Tomonari, S., H. Yoshida, M. Kamakura, K. Kawahito, M. Saitoh, H. kawada, S. Juodkazis, and H. Misawa, Efficient Microvalve driven by a Si-Ni Bimorph, Jpn. J. Appl. Phys, 42, pp 4593-4597, 2003.

[13] Welle, R. P. and B. S. Hardy, Peltier-Actuated microvalve Performance Optimization, 24th Int. Conf Thermoelectrics, 19-23 Jun, El Segundo, California, pp 331-334, 2005.

[14] Liu, Y., M. Kohl, K. Okutsu, and S. Miyazaki, A TiNiPd thin film microvalve for high temperature applications, Materials Science and Engineering A, 378, pp 205-209, 2004.

[15] A Debray, T. Nakakubo, K. Ueda, S. Mogi, M. Shibata, and H. Fujita, A passive micro gas regulator for hydrogen flow control, J. Micromech. Microeng. 15, S202-S209, 2005.

[16] Charles D. Ehrlich and James A. Basford, Recommended practices for the calibration and use of leaks, Journal of Vacuum Science \& Technology A: Vacuum, Surfaces, and Films, 10 (1), pp. 1-17, 1992.

[17] Han, K-H. and A. B. Frazier, Reliability aspects of packaging and integration technology for microfluidic systems, IEEE Trans. Device and materials reliability, 5 (3), pp. 452-457, 2005.

[18] Hugo Nguyen, Johan Bejhed, Lars Stenmark, Johan Köhler and Greger Thornell, Sealing mechanism of a dismountable microsystem-to-macropart fluidic connector for high pressure and a wide range of temperature, submitted to Journal of Micromechanics and Microengineering, May 2006.

[19] Hamrock B J, Schmid S R and Jacobson B 2005 Fundamentals of Machine Elements, 2:nd edition, (Boston: McGraw Hill) chapter 16. 